\title{
FORMATION OF HARD COMPOSITE LAYER ON TOOL STEEL BY LASER ALLOYING
}

Investigations include alloying the PMHSS6-5-3 steel surface layer with carbide and ceramic powders $\mathrm{WC}, \mathrm{VC}, \mathrm{TiC}, \mathrm{SiC}$, $\mathrm{Si}_{3} \mathrm{~N} 4$ and $\mathrm{Al}_{2} \mathrm{O}_{3}$, using the high power diode laser (HPDL). Laser treatment is especially promising for solving contemporary surface engineering problems making it possible to focus precisely the delivered energy in the form of heat in the surface layer. The structural mechanism was determined of surface layers development, effect was studied of alloying parameters, method on structure refinement and influence of these factors on the mechanical properties of surface layer, and especially on its abrasive wear resistance. The fine grained martensite structure is responsible for hardness increase of the alloyed layer. The tribological wear relationships were determined for laser treated surface layers, determining friction coefficient, and wear trace shape developed due to the abrasive wear of the investigated surfaces. Comparison of the laser treatment parameters and tribological properties of surface layer after remelting and alloying with hard particles of the PMHSS6-5-3 steel using the high power diode laser to obtain the optimum service properties is the outcome of the investigations carried out.

Keywords: tool materials, surface treatment, laser, tribology

\section{Introduction}

Market requirements growing nowadays, as well as development of technology, induce to the search of the new possibilities of improvement of the surface layer properties of the tool steels existing hitherto. Reliability of a tool in the technological lines becomes the most important factor; therefore, alternative solutions are sought among the price, availability, and the relatively long tool life. Properties of the surface layer of these steels have to protect tools from deterioration of their service life, and especially they should be characteristic of abrasion resistance at elevated temperature, cyclic mechanical loads, and corrosion action of the machined material [1-3]. However, investigation of the possibility of improving the service properties of tool steels with the martensitic matrix by a conventional change of their chemical composition is very limited nowadays. Modification of the tools' surface layer structure with laser or its laser re-melting, and also by alloying with very hard materials, like carbides and ceramic powders, feature the research directions of the future research on improvement of their properties. Mechanical and tribological properties of alloys obtained in this way are hard to acquire in the conventional technological processes $[4,5]$. High cooling rates are obtained in this process and its end result is the fine-grained material with the super-cooled phases [6-8]. Material transport in the remelting place is under the responsibility of surface tension forces and decide of the emerging morphology of the alloyed surface layer [9-14].

The non-uniform material heating resulting from the laser beam impact causes development of a big surface tension gradient on the surface of the liquid. The force is directed outside from the beam centre where is the highest temperature value to its edge and causes movement of the molten material [4, 6-8]. Thanks to the very precise energy delivery laser radiation makes it possible to carry out the technological operations better or faster within the framework of the technologies known to date. Also it makes it possible to introduce the new technologies which realization is impossible when using the conventional heat treatment. Density of power delivered to the surface layer of the processed materials is lower for the more and more often used High Power Diode Laser compared to its single mode distribution characteristic for other laser types; however, the energy is distributed more uniformly across the rectangular area of the laser beam focus. Mostly used laser technologies include alloying, fusion penetration, and remelting, which provide the highest quality surface coatings with thickness of $0.1 \div 1.5 \mathrm{~mm}$ and very high quality adhesion with the substrate which can be used for the significant part of metal elements made with tolerance below $0.1 \div 0.5 \mathrm{~mm}$, when the progressive flank wear tool life criterion does not exceed $0.1 \div 0.5 \mathrm{~mm}$. Layers made with the laser technique, apart from the very good metallurgical joint with the substrate, provide high corrosion resistance, abrasive wear resistance, high heat resistance and hardness, as well as ductility, plasticity and fatigue resistance, which are difficult or even impossible to obtain with other technologies [6-7], [15-18].

\section{Material and method}

The experiments were made on specimens made from the high speed steel PMHSS6-5-3. The chemical composition

* SILESIAN UNIVERSITY OF TECHNOLOGY, INSTITUTE OF ENGINEERING MATERIALS AND BIOMATERIALS, FACULTY OF MECHANICAL ENGINEERING, 18A KONARSKIEGO STR., 44-100 GLIWICE, POLAND

\# Corresponding author: mirosław.bonek@polsl.pl 
Chemical composition of the PMHSS6-5-3 high speed steel

\begin{tabular}{|c|c|c|c|c|c|c|c|c|c|}
\hline \hline Steel type & \multicolumn{8}{c|}{ Average mass concentration of elements, \% } \\
\hline & $\mathrm{C}$ & $\mathrm{Cr}$ & $\mathrm{W}$ & $\mathrm{Mo}$ & $\mathrm{V}$ & $\mathrm{Co}$ & $\mathrm{Si}$ & $\mathrm{P}$ & $\mathrm{S}$ \\
\hline PMHSS6-5-3 & 1,2 & 4,2 & 6,3 & 5,0 & 3,0 & - & 1,09 & 0,015 & 0,010 \\
\hline
\end{tabular}

Selected properties of powders

\begin{tabular}{|c|c|c|c|c|}
\hline \hline Powder & Average grain size, $\mathrm{mm}$ & Melting point, ${ }^{\circ} \mathrm{C}$ & $\begin{array}{c}\text { Density } \\
\mathrm{g} / \mathrm{cm}^{3}\end{array}$ & $\begin{array}{c}\text { Hardness, } \\
\mathrm{HV}\end{array}$ \\
\hline Tungsten carbide $\mathrm{WC}$ & 5 & 2770 & 15.6 & 2600 \\
\hline Vanadium carbide $\mathrm{VC}$ & 1.5 & 2830 & 5.36 & 2850 \\
\hline Titanium carbide $\mathrm{TiC}$ & 3 & 3140 & 4.25 & 2800 \\
\hline Silicon carbide $\mathrm{SiC}$ & 7 & 2700 & 3.21 & 2100 \\
\hline Silicon nitride $\mathrm{Si}_{3} \mathrm{~N}_{4}$ & 5 & 1900 & 3,44 & 1600 \\
\hline Alumina oxide $\mathrm{Al}_{2} \mathrm{O}_{3}$ & 5 & 2047 & 3.90 & 2300 \\
\hline
\end{tabular}

of the steel is presented in Table 1. The investigated steel was molten in the electric vacuum furnace at the pressure of about $1 \mathrm{~Pa}$, cast into ingots weighing about $250 \mathrm{~kg}$, and were roughed at the temperature range $1100-900^{\circ} \mathrm{C}$ into the O.D. $75 \mathrm{~mm}$ bars, which were soft annealed. After making by machining the specimens they were heat treated. The specimens were austenitized on the salt bath furnace and tempered in the chamber furnace in the protective atmosphere - argon. The specimens were gradually heated to the austenitizing temperature with the isothermic stops at 650 and $850^{\circ} \mathrm{C}$ for $15 \mathrm{~min}$. Further they were austenized for $30 \mathrm{~min}$ at the temperature of $1200^{\circ} \mathrm{C}$ and cooled in hot oil. The specimens were tempered twice after quenching, each time for 2 hours, at the temperature of $560^{\circ} \mathrm{C}$ and next at $545^{\circ} \mathrm{C}$. Surfaces of specimens were sand blasted and machined on magnetic grinder. On specimen surface two parallel grooves, deep for $0.5 \mathrm{~mm}$ of triangular shape (with angle of $45^{\circ}$ ) were machined. The grooves were located along sample axis and distance between them was ca. $1.0 \mathrm{~mm}$. Such prepared grooves were filled with $\mathrm{WC}, \mathrm{VC}, \mathrm{TiC}, \mathrm{SiC}, \mathrm{Si}_{3} \mathrm{~N}_{4}$ and $\mathrm{Al}_{2} \mathrm{O}_{3}$ particles. Properties of the powders are presented in Table 2.

Surface of specimens of the PMHSS6-5-3 steel fixed in a turntable was remelted with the Rofin DL 020 high power diode laser (HPDL) beam with parameters specified in Table 3.

TABLE 3

Specifications for the HDPL, Rofin DL 020

\begin{tabular}{|c|c|}
\hline \hline Wavelength of the laser radiation, $\mathrm{nm}$ & $808 \pm 5$ \\
\hline $\begin{array}{c}\text { Maximum output power of the laser beam (continuous } \\
\text { wave), W }\end{array}$ & 2100 \\
\hline Power range, $\mathrm{W}$ & $100-2100$ \\
\hline Focal length of the laser beam, mm & $82 / 32$ \\
\hline $\begin{array}{c}\text { Laser spot size, mm } \\
\text { Power density range in the laser beam focal plane, } \\
\mathrm{kW} / \mathrm{cm}^{2}\end{array}$ & $0.8-36.5$ \\
\hline
\end{tabular}

Rofin DL 020 is a versatile laser, used in materials engineering, among others, for: laser cladding, welding, remelting and enrichment of surface. The laser system consists, among others, of the following modules: rotating work table and movable in the $\mathrm{X}-\mathrm{Y}$ plane, nozzle with the feeder of powder for enrichment or pad welding, protective gas nozzle, laser head, power supply and cooling systems, and the computer system controlling the laser operation and work table positioning. The laser beam dimensions were $1.8 \times 6.8$ $\mathrm{mm}$. Remelting was carried out perpendicular to the longer side of the beam with the multimode energy distribution, which makes it possible to obtain the wide remelting face. The working laser focal length, measured from the head protective glass, was $92 \mathrm{~mm}$. It was found out based on the preliminary investigations that the laser beam feed rate at which the process is stable is $0.5 \mathrm{~m} / \mathrm{min}$ Further experiments were carried out at the constant remelting rate, changing the laser beam power in the $0.7 \div 2.1 \mathrm{~kW}$ range during remelting the surface layer of the test pieces, and in the $0.7 \div 2.1 \mathrm{~kW}$ range during alloying of the test pieces. It was revealed experimentally during the investigations that presence of the argon blow-in with the flow rate of $201 /$ min through the $\varnothing$ $12 \mathrm{~mm}$ circular nozzle directed oppositely in respect to the remelting direction provides the optimum remelting zone protection.

The test of dry wear resistance with the pin-on-disk method were made on the computer controlled CSEM High Temperature Tribometer. Friction force between the ball and the disk was measured during the test run. Basing on the preliminary experiments the following test conditions were assumed: the smallest scatter of results and stable tribological characteristics were obtained for the counter-specimen in the form of the $6 \mathrm{~mm}$ diameter ball from the aluminium oxide $\mathrm{Al}_{2} \mathrm{O}_{3}$. In this test the stationary ball was pressed against the disk rotating in the horizontal plane with the force of $10 \mathrm{~N}$. The rubbing speed was $0.5 \mathrm{~m} / \mathrm{sec}$, friction radius was from 11 to $22 \mathrm{~mm}$, and the optimum friction distance was determined as $1000 \mathrm{~m}$. The temperature of the environment was assumed as $23^{\circ} \mathrm{C}$, and the relative air humidity as $50 \%$. Measurement of the specimens mass loss was made on the Mettler AT 201 electronic weigher, cleaning the specimens form the wear products in the friction zone with the air jet. The analysis of the counter-specimen wear land $\left(\mathrm{Al}_{2} \mathrm{O}_{3}\right.$ ball) was made using 
the light microscope with the Image - Pro Measure Version 1.3 image analysis system at magnification 50x. Wear profiles of the specimens were made on the Taylor - Hobson Form Talysurf $120 \mathrm{~L}$ laser profile measurement in three planes every $120^{\circ}$. Metallographic examination of the material structures after surface laser alloying were made on a Zeiss LEICA MEF4A light microscope with magnifications from 50 to $500 x$. A Leica-Qwin computer image analysis system was used for thickness examination of the particular zones of the surface layer. Structure of the developed coatings were examined with SUPRA 25 scanning electron microscope (SEM). Hardness tests were made using Rockwell method in $\mathrm{C}$ scale on specimens subjected to the standard heat treatment and alloyed using the high power diode laser at various parameters, making 10 measurements for each condition and calculating their average value. Test results were analysed statistically. Hardness was measured on the ground and bead face of specimens. Coating microhardness was tested on the FM-700 microhardness tester. The tests were carried out at $0.01 \mathrm{~N}$ load, making the necessary number of indents on the section of each examined specimen, correspondingly to the structural changes depth in the material surface layer. The microhardness tests were made along the lines perpendicular to specimens' surfaces, along the run face axis.

\section{Investigation results and discussion}

It was revealed, based on the metallographic examinations, that the structure of the material solidifying after laser remelting and alloying is characteristic of occurrences of areas with the diversified morphology connected with crystallisation of the steel. Big dendrites occur in the boundary zone between the solid and liquid phases, whose main axes are oriented according to the heat abstraction directions (Fig. 1). The characteristic repeated crystal growth direction change is observed for these areas. Structure of fine equiaxial crystals with the carbide lattice develops in the central zone of the fused area where heat abstraction takes place in all directions (Fig. 2).

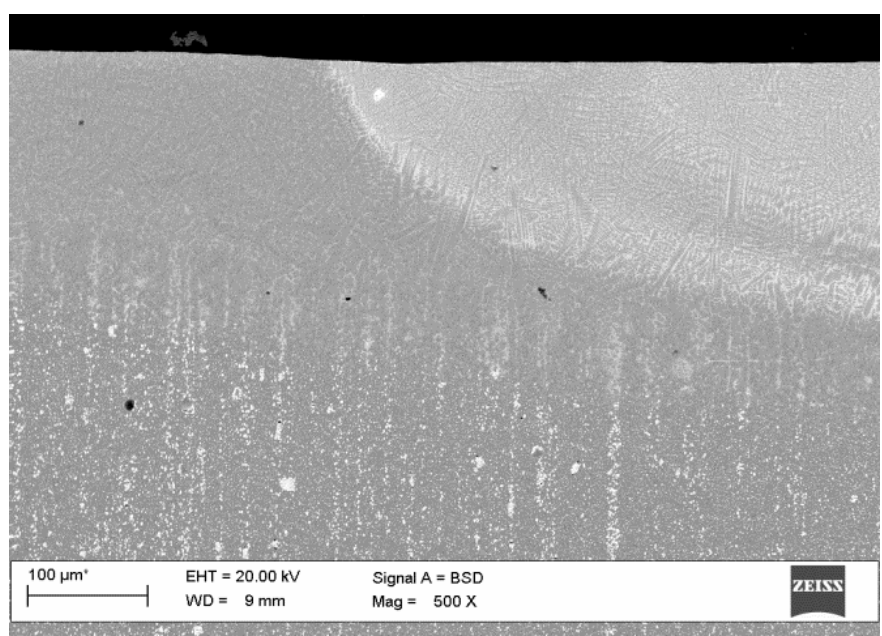

Fig. 1. Surface shape and remelting depth of the high speed steel PMHSS6-5-3 test piece transverse sections with the $\mathrm{Al}_{2} \mathrm{O}_{3}$ particles with laser power value $1.4 \mathrm{~kW}$

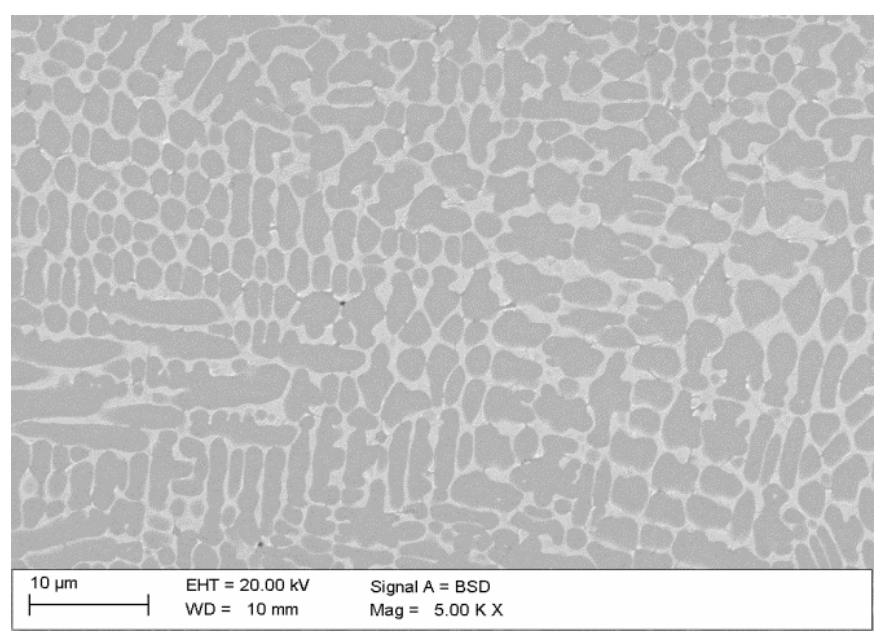

Fig. 2. Surface layer of the high speed steel PMHSS6-5-3 steel after laser remelting with the $\mathrm{Al}_{2} \mathrm{O}_{3}$ particles with the scanning rate of 0.5 $\mathrm{m} / \mathrm{min}$ and laser beam power of $1.7 \mathrm{~kW}$, remelted zone

Laser treatment of surface layers results in the steel surface hardness increase of all investigated steels and this effect is achieved thanks to occurrences of phase transformations connected closely with the heat removal rate from the remelted zone. The factor controlling in great measure the cooling rate is thickness of the remelted layer, dependant on the absorbed radiation energy and the time period of the laser beam impact on the material. Only the laser power affects the energy delivered to the surface layer with the constant remelting rate. At the low power of the laser beam the remelting depth is small; therefore heat removal rate is the highest. High cooling rate causes occurrences of the super-fast phase transformations; therefore, the fine-grained martensite structure occurs in the material, responsible for hardness growth. Microhardness growth was revealed, based on microhardness tests on the transverse section of laser runs versus distance from the surface of the examined steel test pieces showed hardness increases (Figs. $3,4)$. The high average microhardness (Fig. 5) increase in the remelted zone surface layer was observed for laser beam power of $2.1 \mathrm{~kW}$. In the case of alloying, the highest microhardness was obtained for the steel surface layer alloyed with the VC particles, for which the average microhardness increase is $1392 \mathrm{HV}_{0,1}$, when the laser power used for alloying was 1.4 $\mathrm{kW}$. Figure 6 presents the HRC hardness tests results of the surface layer after remelting with the HPDL high power diode laser using the carbide and ceramic particles. It was observed that increase of the laser power causes inundation of a larger amount of the carbide and ceramic particles; and therefore, increased the surface layer hardness, which was confirmed by examination on the light microscope with the Leica-Qwin computer image analysis system, and also by observations on the scanning microscope. Hardness for the native material after heat treatment is about $64 \mathrm{HRC}$, whereas after alloying with vanadium carbide it is about $74 \mathrm{HRC}$. The examined specimens were tribologically damaged due to action of the counterspecimen with the load of $10 \mathrm{~N}$, along the friction distance of $1000 \mathrm{~m}$. To analyse changes of the friction coefficient, plots of friction coefficient $\mu$ as function of friction distance were made. The value of the friction coefficient was evaluated as the average from the instantaneous values obtained for the part 
of the characteristics relevant for the stabilised friction. The significant effect of laser alloying with the power 0.7, 1.4 and $1.7 \mathrm{~kW}$ of the surface layer on decrease of friction coefficient, compared to the surface after remelting was observed (Fig. 7). The tests with the gravimetric method were carried out weighing each specimen three times before the experiment and after the test and their results were statistically analysed. Test results of the average specimens mass loss due to friction in the ball - disk pair for the surface layer obtained at various laser beam power values are presented in figure 8 . It turns out from the analysis of the mass loss of specimens, depending on the laser beam power used for alloying of the surface layer that the mass wear of the alloyed $\mathrm{VC}$ alloyed specimens was about $50 \%$ smaller and was from $0.38 \mathrm{mg}$ to $0.45 \mathrm{mg}$ in comparison with the material after laser remelting, for which this value was $0.81 \mathrm{mg}$. The laser beam power does not have any clear effect on the mass wear of the investigated specimens.

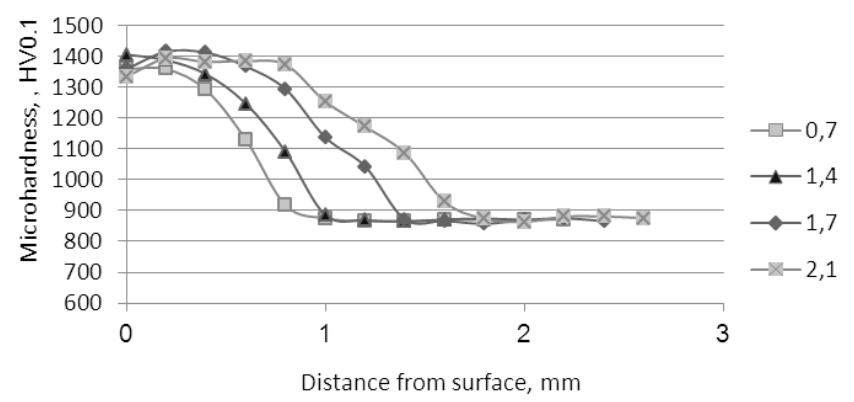

Fig. 3. Change in microhardness of the high speed steel PMHSS6-5-3 surface layer after alloying with $\mathrm{VC}$ and laser beam power of $0.7,1.4$, 1.7 and $2.1 \mathrm{~kW}$

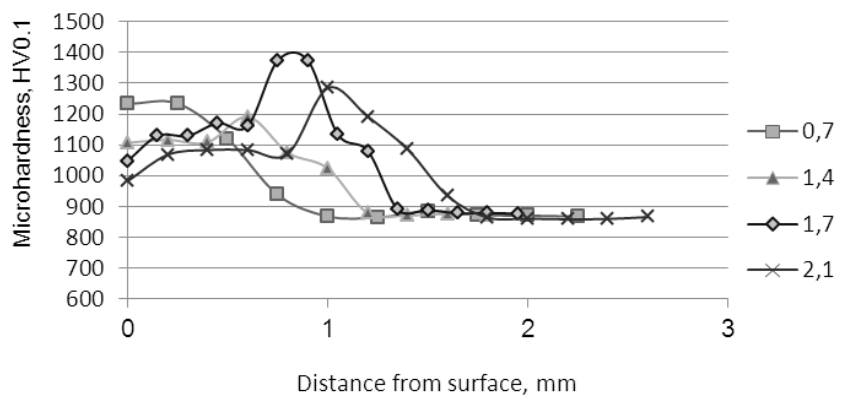

Fig. 4. Change in microhardness of the high speed steel PMHSS6-5-3 surface layer after alloying with $\mathrm{SiC}$ and laser beam power of $0.7,1.4$, 1.7 and $2.1 \mathrm{~kW}$

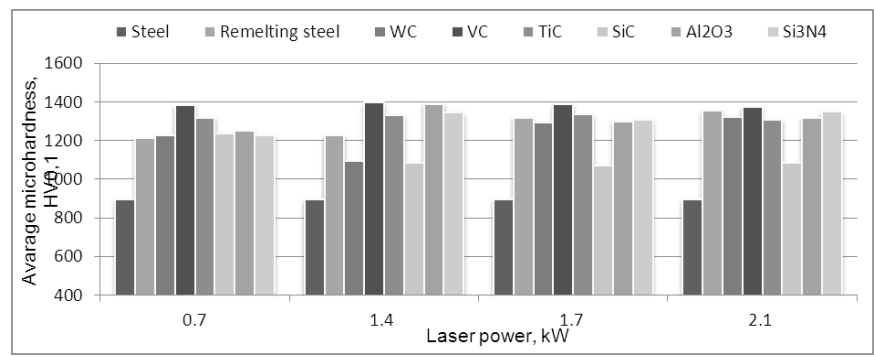

Fig. 5. Avarage microhardness for the high speed steel PMHSS6-5-3 remelted and alloyed with the $\mathrm{WC}, \mathrm{VC}, \mathrm{TiC}, \mathrm{SiC}, \mathrm{Si} 3 \mathrm{~N} 4$ and $\mathrm{Al}_{2} \mathrm{O}_{3}$ particles with the scanning rate of $0.5 \mathrm{~m} / \mathrm{min}$ and laser beam power of $0.7,1.4,1.7$ and $2.1 \mathrm{~kW}$

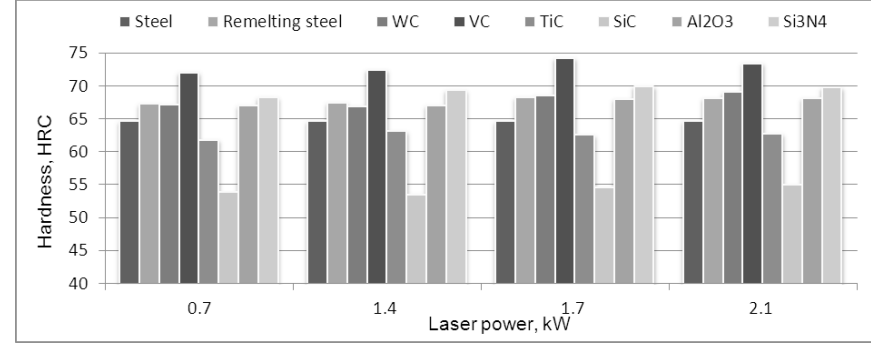

Fig. 6. Avarage hardness for the high speed steel PMHSS6-5-3 remelted and alloyed with the $\mathrm{WC}, \mathrm{VC}, \mathrm{TiC}, \mathrm{SiC}, \mathrm{Si} 3 \mathrm{~N} 4$ and $\mathrm{Al}_{2} \mathrm{O}_{3}$ particles with the scanning rate of $0.5 \mathrm{~m} / \mathrm{min}$ and laser beam power of $0.7,1.4,1.7$ and $2.1 \mathrm{~kW}$

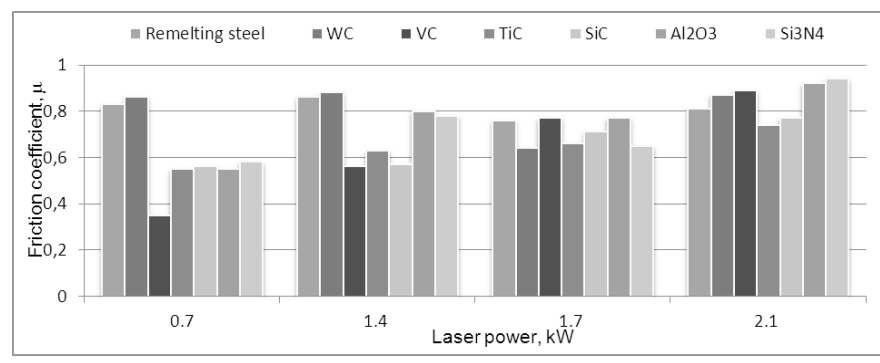

Fig. 7. Comparison of the friction coefficient measurement results depending on the laser beam power used for alloying the steel

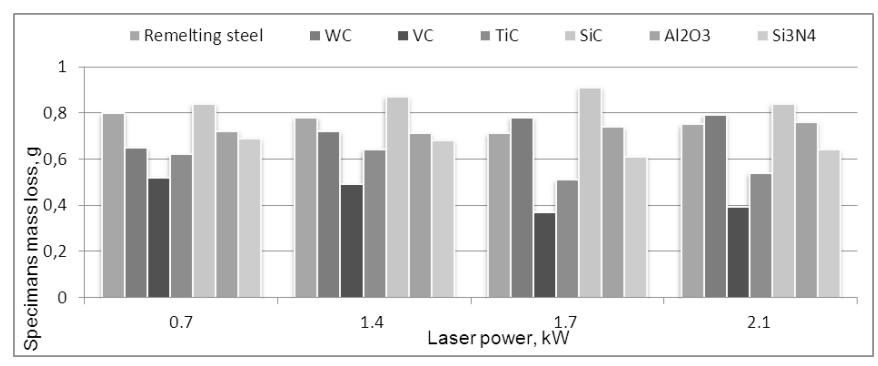

Fig. 8. Measurement results of the average specimen mass loss depending on the laser beam power and alloying particles

The results of the counter-specimen $\left(\mathrm{Al}_{2} \mathrm{O}_{3}\right.$ ball, Fig. 9) wear land area analysis during the tests of the tribological properties of the ball - disk pair are shown in Figure 10. Increase in the counter-specimen wear land area was observed $\left(0.43\right.$ to $\left.0.88 \mathrm{~mm}^{2}\right)$ in the contact with the laser alloyed surface layer. The counter-specimen land wear after the contact with the PMHSS6-5-3 steel after laser remelting is about three times smaller (about $0.29 \mathrm{~mm}^{2}$ ). The laser beam power during melting does not have a meaningful influence on the wear land of the counter-specimen from $\mathrm{Al}_{2} \mathrm{O}_{3}$. For the tribological assessment of the examined surface layer the linear wear was measured using the wear profiles. The exemplary surface layer wear profiles of the steel are shown in Figures 11 and 12. The influence of laser alloying was found out on the depth of the transverse section of the wear path, which for the remelted material was about $4 \mu \mathrm{m}$, whereas for the surface layer alloyed by $\mathrm{TiC}$ carbides with the laser beam with the $1.7 \mathrm{~kW}$ power it achieved value of $2,0 \mu \mathrm{m}$. 


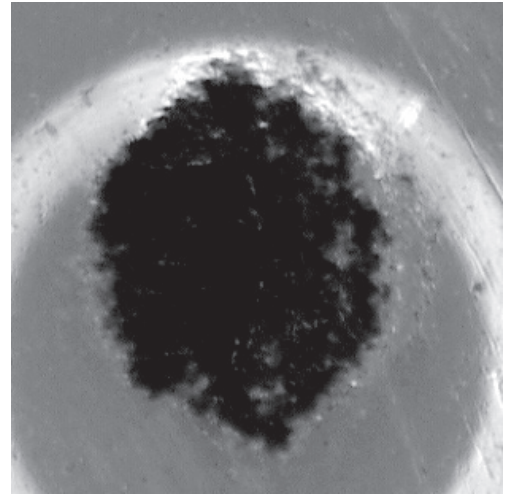

Fig. 9. The $\mathrm{Al}_{2} \mathrm{O}_{3}$ counter-specimen wear after $1000 \mathrm{~m}$ of friction distance with the surface layer of the PMHSS6-5-3 steel after TiC alloying with the $2.1 \mathrm{~kW}$ laser beam; travel speed $-0,5 \mathrm{~m} / \mathrm{s}$

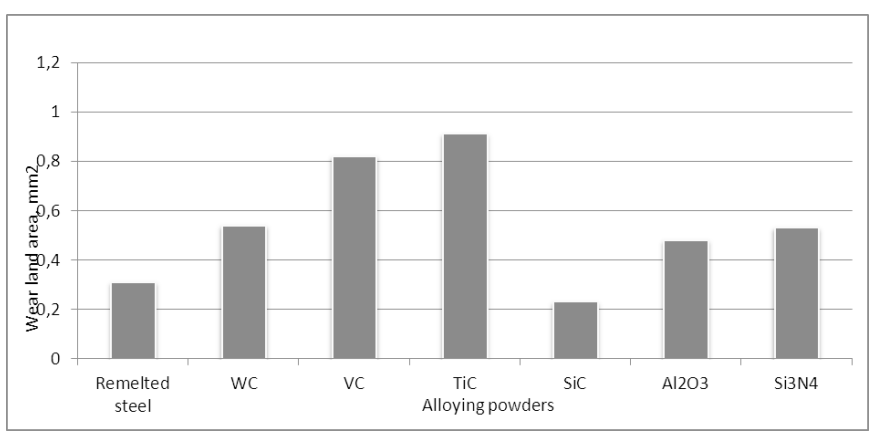

Fig. 10. Comparison of the surface area of the $\mathrm{Al}_{2} \mathrm{O}_{3}$ counter-specimen wear

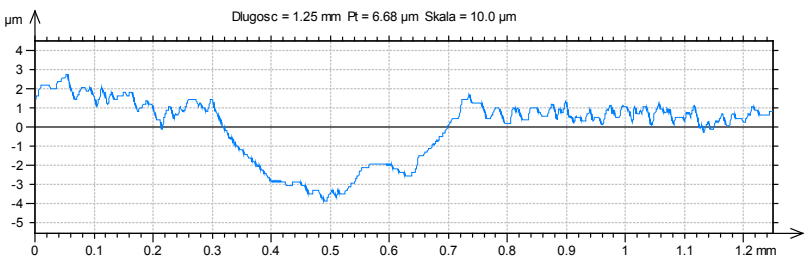

Fig. 11. Exemplary wear profile of PMHSS6-5-3 steel surface layer after remelting with the $1.7 \mathrm{~kW}$ laser beam

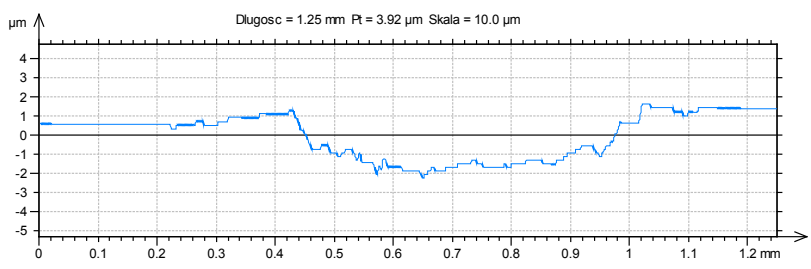

Fig. 12. Exemplary wear profile of PMHSS6-5-3 steel surface layer after TiC alloying with the $1.7 \mathrm{~kW}$ laser beam

\section{Conclusions}

Investigations within the framework of this article include employment of the high power diode laser in the remelting and alloying process of the PMHSS6-5-3 steel surface layers. The goal of this research is to learn the structure transformations occurring during the remelting and alloying processes and the tribological properties of the surface layers obtained in this way. Tests were made on test pieces that were remelted and alloyed with $\mathrm{WC}, \mathrm{VC}, \mathrm{TiC}, \mathrm{SiC}, \mathrm{Si} 3 \mathrm{~N} 4$ and $\mathrm{Al}_{2} \mathrm{O}_{3}$ particles. The surface layer remelting experiments of the PMHSS6-5-3 steel carried out with the high power diode laser (HPDL) indicate that it is possible to obtain the friction coefficient smaller than about $15 \%$ in the pair of $\mathrm{Al}_{2} \mathrm{O}_{3}$ with the laser remelted surface layer of the steel. Employment of laser remelting leads to decrease in the mass wear of specimens during the test, due to the slower release of the wear products. The analysis of the wear profiles of the surface layer revealed decrease in the profile depths for the laser remelted materials. No meaningful effect of the laser beam power during remelting was found on the tribological properties of the surface layer of the PMHSS6-5-3 steel. Due to the martensitic transformation of the PMHSS6-5-3 high speed steel subjected to remelting and alloying with carbides and ceramic particles steel hardness growth occurs usually compared to hardness of about $64 \mathrm{HRC}$ after the conventional heat treatment. The maximum hardness of $74 \mathrm{HRC}$ the investigated steel achieves in case of alloying with the vanadium carbide with the laser power of 1.7 $\mathrm{kW}$. The average micro-hardness of the surface layers subjected to laser treatment is up to about $80 \%$ higher in case of the VC carbide than in case of the native material. The hardness changes of the surface layers obtained by remelting and alloying with WC, VC, TiC, $\mathrm{SiC}, \mathrm{Si}_{3} \mathrm{~N}_{4}$ and $\mathrm{Al}_{2} \mathrm{O}_{3}$ using the high power diode laser are accompanied with the improved tribological properties compared to the conventionally heat treated steel. The highest wear resistance, more than 1.5 times higher than that of the native material, was revealed in case the steel alloyed with vanadium carbide.

Results of literature studies and own research have demonstrated that development of surface layers on the PMHSS6-5-3 steel in the processes of laser remelting and alloying with hard particles using the high power diode laser improves the tribological properties significantly. This is possible thanks to the super-fast phase transformations occurring then, compared to steel subjected to the conventional heat treatment. This ensures improvement of steel properties consisting in the increase of hardness and abrasion wear resistance of the surface layer.

\section{Acknowledgements}

This publication was financed by the Ministry of Science and Higher Education of Poland as the statutory financial grant of the Faculty of Mechanical Engineering SUT.

\section{REFERENCES}

[1] J. Mateos, J.M. Cuetos, E. Fernandez, R. Vijande, Wear. 239, 274-281 (2000)

[2] T.R. Jervis, Surf Coat Tech. 89, 158-164 (1997).

[3] J. Kusiński, Lasers and their employment in materials engineering, Publisher „Akapit”, Kraków, 2000, (in Polish)

[4] J. Kusiński, Appl Surf Sci. 86, 317-322 (1995).

[5] J. Kusiński, J Mater Process Tech. 64, 239-246 (1997).

[6] M. Bonek, G. Matula, L.A. Dobrzanski, Adv Mat Res. 291294, 1365-1368 (2011).

[7] M. Bonek, L.A. Dobrzański, Mater Sci Forum, 654-656, 18481851 (2010). 
[8] T. Tański, Materialwiss Werkst. 45, (5), 333-343 (2014).

[9] L.A. Dobrzański, D. Pakuła, Mater Sci Forum, 513, 119-133 (2006).

[10] M.C. Oh, H. Yeom, Y. Jeon, B. Ahn, Arch Metall Mater. 60, (2), 1331-1334 (2015).

[11] M. Krol, M. Bilewicz, J.C. Viana, L.A. Dobrzanski, Mater Sci Forum. 587-588, 553-557 (2008).

[12] G. Matula, L.A. Dobrzański, A. Várez, B. Levenfeld, J.M. Torralba, J Mater Process Tech. 162, 230-235 (2005).

[13] Z. Brytan, J. Niagaj, Chiang Mai J Sci. 40, (5), 923-937 (2013).
[14] N. Radek, J. Konstanty, Arch Metall Mater. 57, (3), 665-670 (2012).

[15] L.A. Dobrzański, D. Pakuła, J. Mikuła, K. Gołombek, Int. J. Surface Science and Engineering, 1 (1), 111-124 (2007).

[16] L.A. Dobrzański, D. Pakuła, Mater. Sci. Forum. 513, 119-133 (2006).

[17] S. Lesz, R. Szewczyk, D. Szewieczek, A. Bieńkowski, J Mater Process Tech. 157-158, 743-748 (2004).

[18] D. Szewieczek, S. Lesz, J Mater Process Tech. 162, 254-259 (2005). 